\title{
Tensiones existentes entre el reconocimiento constitucional de la diversidad étnica y cultural y la protección de los derechos fundamentales, derivado de las prácticas culturales, en lo relacionado con la prohibición del uso de la hoja de coca por parte de la comunidad Nasa en el departamento del Cauca
}

\footnotetext{
Elías Castro Blanco

Filósofo por la Universidad Nacional de Colombia. Magister en Filosofía del Derecho y Teoría Jurídica por la Universidad Libre. Magister en Historia por la Pontificia Universidad Javeriana. Especialista en Filosofia del Derecho y Teoría Juridica por la Universidad Libre. Doctor en Estudios Politicos por la Universidad Externado de Colombia. Correo electrónico:

eliascastroblanco@gmail.com
}

Juan Carlos Mora González

Filósofo por la Universidad del Quindio. Abogado. Docente de las asignaturas de Derecho Penal, Lógica, Metodología de Investigación, Sociología, Doctrinas Politicas y Filosofía de la Ciencia en varias universidades, como: Universidad del Valle, Universidad del Quindio, Gran Colombia y Autónoma. Correo electrónico: juancarlosmoragonzalez@gmail.com

\begin{abstract}
Resumen
Mediante el desarrollo de esta investigación se espera contribuir con el análisis del consumo de hoja de coca como patrimonio cultural inmaterial en el pueblo Nasa, del departamento del Cauca; este objeto de estudio se encuentra inscrito en las categorías de análisis básicas, a saber: multiculturalidad y plurietnia, como se reconoce en la Constitución Política de Colombia. Esta práctica se encuentra en abierta oposición a la prohibición internacional, ratificada en los convenios suscritos por Colombia y Estados Unidos, en el marco de las políticas de erradicación del narcotráfico. De conformidad con lo anterior, la tesis por defender consiste en que frente a la ingesta de coca por parte de la comunidad Nasa, el Estado colombiano debe privilegiar sus usos médicos, rituales y simbólicos, y velar por la protección de estos pueblos, antes que las presiones externas, amparadas en acuerdos como el de la Junta Interamericana de Fiscalización de Estupefacientes (JIFE). El examen que aquí se hace de esta situación permitirá establecer si el consumo y comercialización de alimentos con base en la hoja de coca puede ser considerado manifestación del patrimonio cultural inmaterial de la Nación, así como también de qué manera y hasta qué punto la comunidad internacional puede prohibir y tratar de erradicar su uso, dado que forma parte de las tradiciones milenarias del pueblo Nasa o Páez, asentado en el departamento del Cauca.

Palabras clave: Hoja de coca, manifestación cultural, autonomía indígena, patrimonio cultural inmaterial, plurietnia, multiculturalidad, Corte Constitucional, tratados, Junta de Fiscalización de Estupefacientes.
\end{abstract}

Summary

By developing this research is expected to contribute to the analysis of consumption of coca as intangible cultural heritage in the Nasa people, the department of Cauca; this object of study is registered in the categories of basic analysis, namely: multiculturalism and plurietnia, as recognized in the Constitution of Colombia. This practice is in open opposition to the international ban, ratified in the agreements signed by Colombia and the United States, within the framework of policies to eradicate drug trafficking. In accordance with this, the thesis is that defend against cocaine intake by the Nasa community, the Colombian State must prioritize their doctors, rituals and symbolic uses, and ensure the protection of these peoples, rather than external pressures, covered in agreements such as the Inter-American Narcotics Control Board (INCB). The test here makes this situation will establish whether consumption and marketing of foods based on the coca leaf can be considered manifestation of intangible cultural heritage of the nation, as well as how and to what extent the international community You can prohibit and try to eradicate their use, as part of the ancient traditions of the people Nasa or Paez, seated in the department of Cauca.

Keywords: Coca leaf, cultural manifestation, Indigenous Autonomy, Intangible Cultural Heritage, Plurietnia, Multiculturalism, Constitutional Court, Treaties Narcotics Control Board.

Résumé

En développant cette recherche devrait contribuer à l'analyse de la consommation de la coca en tant que patrimoine culturel immatériel dans le peuple Nasa, le département de Cauca; cet objet d'étude est inscrit dans les catégories de l'analyse de base, à savoir: le multiculturalisme et plurietnia, tel que reconnu dans la Constitution de la Colombie. Cette pratique est en opposition ouverte à l'interdiction internationale, ratifié dans les accords signés par la Colombie et les Etats-Unis, dans le cadre des politiques visant à éradiquer le trafic de drogue. Conformément à cela, la thèse est que défendre contre la consommation de cocaïne par la communauté Nasa, l'Etat colombien doit prioriser leurs médecins, les rituels et les usages symboliques, et d'assurer la protection de ces peuples, plutôt que pressions extérieures, couvertes par des accords tels que le Conseil de contrôle des stupéfiants interaméricaine (OICS). Le test ici rend cette situation va établir si la consommation et la commercialisation des aliments en fonction de la feuille de coca peuvent être considérés comme la manifestation du patrimoine culturel immatériel de la nation, ainsi que comment et dans quelle mesure la communauté internationale Vous pouvez interdire et essayer d'éradiquer leur utilisation, dans le cadre des anciennes traditions du peuple Nasa ou Paez, assis dans le département de Cauca.

Mots-clés: Feuille de Coca, manifestation culturelle, l'autonomie indigène, du patrimoine culturel immatériel, Plurietnia, le multiculturalisme, la Cour constitutionnelle, du Conseil de contrôle des stupéfiants traités.

Recibido: 24 de septiembre de 2014, Aprobado: 29 de octubre de 2014 . 



\section{Tensiones existentes entre el reconocimiento constitucional de la diversidad étnica y cultural y la protección de los derechos fundamentales, derivado de las prácticas culturales, en lo relacionado con la prohibición del uso de la hoja de coca por parte de la comunidad Nasa en el departamento del Cauca*}

Elias Castro Blanco

Juan Carlos Mora González

\section{INTRODUCCIÓN}

La Constitución Política de Colombia - resultado de la Asamblea Nacional Constituyente, órgano en el que diversos grupos y fracciones participaron en su reforma-estuvo desde un principio ligada a propuestas incluyentes. El reconocimiento de las distintas etnias constituye en principio un logro significativo, en tanto los grupos, partidos y movimientos allí representados contribuyeron a forjar una idea de nacionalidad desde sus visiones omnicomprensivas de mundo. Los postulados basados en el tratamiento indígena fueron los siguientes: reconocimiento de las distintas etnias, apoyo a su autonomía y estilos propios de gobierno, protección a las tierras comunales y a las formas de propiedad solidaria y asociativa, protección a los recursos naturales y protección de las riquezas culturales. Cabe resaltar que en esta Carta, los derechos de los pueblos indígenas y valores culturales hicieron tránsito a rango constitucional, como consta en el artículo 7 de la Carta Magna.

La Constitución de 1991 determinó un escenario nuevo y otro tipo de reivindicaciones para las comunidades y pueblos indígenas, afrocolombianos, raizales y demás que conforman la Nación; pasó de ser una Constitución cuyo ideal se basaba en la integración y homogeneidad racial, cultural y nacional, a definir la diversidad étnica y cultural, como valor cultural e inmaterial. En este orden, la jurisdicción especial indígena en la nueva Constitución tiene tres connotaciones específicas: a) Reconoce la diversidad étnica y el pluralismo jurídico en el territorio nacional. b) Establece la necesidad de límites mínimos a la necesaria autonomía jurisdiccional de estas comunidades. Y c) Prevé la obligatoriedad de algunos mecanismos de coordinación con la jurisdicción nacional, bajo el imperativo de proteger y de garantizar la diversidad étnica y cultural que proclama el artículo 7.

En síntesis, los logros más significativos reconocidos en esta Carta Magna pueden agruparse en los siguientes:

El presente texto es producto del proyecto de investigación externo de la Fundación Universitaria Autónoma de Colombia (FUAC), Facultad de Ciencias Humanas; Línea memoria colectiva, historia e identidad. Proyecto: La hoja de coca como patrimonio cultural inmaterial, 2014. 
- Culturales: reconocimiento y protección por el Estado a la diversidad étnica y cultural (art. 7); a las lenguas indígenas en sus territorios, lo mismo que a la etnoeducación (educación indígena) y a la enseñanza bilingüe (art. 10 e inciso 5 del art 68); libertad de conciencia y de cultos (art. 8 y 19); defensa del patrimonio cultural (art. 72); reconocimiento a su propia justicia en sus jurisdicciones (art. 246); igualdad y dignidad de sus culturas como fundamento de la nacionalidad (art. 70).

- Territoriales: reconocimiento de los resguardos como propiedad colectiva de la tierra con sus características de inalienable, imprescriptible e inembargable (art. 63); a los territorios indígenas como entidades territoriales de la nación y de autonomía para darse su propio gobierno y conseguir su desarrollo (art. 286).

- Ambientales y de explotación de recursos naturales: derecho a tener ambiente sano (art. 79); a conservar los recursos naturales y la garantía de desarrollo sostenible (art. 80), esto incluye consulta previa para explorar los recursos en sus territorios.

- Políticos y sociales: derecho de los indígenas a ocupar dos curules en el Senado de la República (art. 171); a poseer doble nacionalidad en el caso de los indígenas que habitan en zonas de frontera (art. 96, literal c).

- Económicos: asimilación de los resguardos a municipios para que participen de los ingresos corrientes (transferencias) de la Nación (art. 357).

El reconocimiento de derechos en la Constitución es considerado un avance significativo, sobre todo los del primer grupo y para los efectos de esta investigación en especial el artículo $7^{\circ}$, al consagrar que el Estado colombiano reconoce y protege la diversidad étnica y cultural de la Nación, con lo que no solo se integró plenamente a los indígenas al conglomerado social del país sino la protección de sus derechos cuando estos sean conculcados. A su vez, el artículo 8 predica lo siguiente: "Es obligación del Estado y de las personas proteger las riquezas culturales y naturales de la Nación”. De lo anterior se deriva el vínculo contractual que obliga al Estado colombiano a proteger las riquezas culturales, que según los constitucionalistas forman parte del elemento sicológico, ligado estrechamente al artículo 70 que establece:

La cultura en sus diversas manifestaciones es fundamento de la nacionalidad.

El Estado reconoce la igualdad y dignidad de todas las que conviven en el país.

El Estado promoverá la investigación, la ciencia, el desarrollo y la difusión de los valores culturales de la Nación.

De conformidad con lo anterior, si la cultura es el fundamento de la nacionalidad en la que se encuentran insertas diversas manifestaciones de vida y costumbres ancestrales de los pueblos aborígenes que habitan el territorio colombiano, mal haría el Estado en abolir prácticas milenarias como el cultivo de la hoja de coca con propósitos medicinales y rituales, como es usual en la cultura Nasa del departamento del Cauca. 
Los instrumentos de protección están dados en buena parte en los artículos 7, 8 y 70 de la Constitución, con fundamento en su existencia y manifestaciones forman parte del acervo cultural colombiano, transmitido de generación en generación, y constituyen por demás parte esencial de la existencia humana. Así, al amparo de estos pétreos principios constitucionales, el reconocimiento cultural del consumo de bebidas y productos derivados de la hoja de coca, considerados no alucinógenos por las comunidades indígenas, así como su posible expansión en territorios no indígenas, es una realidad que amerita ser analizada en detalle, a la luz de los principios derivados de la Carta Política del 91, plasmada en la Ley 397 de 1997, más conocida como Ley General de Cultura.

En la actualidad, un hecho generalizado consiste en afirmar que no existe una Constitución que plantee de manera unívoca la titulación de los derechos a nivel individual o colectivo, pues en buena medida estos aparecen incorporados en un catálogo de principios constitucionales o declaraciones de derechos, cuando no de manera implícita o tácita; así, sería una insensatez pretender abolir normas que forman parte de un derecho consuetudinario, como las prácticas culturales ancestrales relacionadas con el cultivo y la masticación de hoja de coca por una gran mayoría de las comunidades indígenas americanas.

Esta breve presentación sirve como preámbulo para señalar las tensiones existentes en materia de derechos reconocidos constitucionalmente, como: a) Diversidad étnica y cultural. b) Jurisdicción indígena - autonomía, y c) Plurietnicidad, frente a la prohibición explícita por parte del Estado colombiano del consumo de la hoja de coca por la comunidad Nasa. Este patrimonio cultural de la Nación, como práctica ancestral de los pueblos indígenas, entra en colisión no solo con las normas que prohíben de manera explícita el uso de la hoja de coca, sino con el bloque de constitucionalidad que ampara los siguientes derechos: el libre desarrollo de la personalidad y la protección de la diversidad étnica y cultural, entre otros.

\section{PLANTEAMIENTO DEL PROBLEMA}

Buena parte de los pueblos indígenas de Colombia consumen hoja de coca, tradición que se encuentra protegida constitucionalmente, en especial cuando prescribe que "la cultura en sus diversas manifestaciones es fundamento de la nacionalidad"; sin embargo, siendo este consumo parte del patrimonio cultural de la Nación, no está incluido en la lista representativa de manifestaciones.

El tema del cultivo, uso y consumo de la hoja de coca cobra importancia en instrumentos internacionales como la Convención Única sobre Estupefacientes (CUE) de las Naciones Unidas, celebrada en Nueva York el 30 de marzo de 1961, en cuyo Preámbulo plantea "la preocupación por la salud física y moral de la humanidad" y reconoce que "la toxicomanía constituye un mal grave para el individuo y entraña un peligro social y económico para la humanidad". En lo tocante a este asunto existen tres convenciones de las Naciones Unidas: la Convención Única de 1961 sobre 
Estupefacientes, la Convención sobre Sustancias Psicotrópicas, firmado en 1971, que pretendía luchar contra el consumo de estupefacientes en los años sesenta y setenta, y la Convención de las Naciones Unidas contra el Tráfico Ilícito de Estupefacientes y Sustancias Psicotrópicas, de 1988. La intencionalidad manifiesta con la ratificación de estas convenciones, consiste en restringir el uso de la hoja de coca que en nuestro país adquiere connotaciones penales, como en efecto se traduce en la Ley 30 de 1986.

En materia de reglamentación de cultivos la mencionada ley señala lo siguiente:

“Artículo $7^{\circ}$. El Consejo Nacional de Estupefacientes reglamentará los cultivos de plantas de las cuales se produzcan sustancias estupefacientes y el consumo de éstas por parte de las poblaciones indígenas, de acuerdo con los usos y prácticas derivadas de su tradición y cultura". Así pues, en ciertos aspectos esta normatividad tiene en cuenta el uso que tradicionalmente han hecho las comunidades indígenas de la hoja de coca, lo que constituye un avance en esta materia.

\section{Descripción del problema}

Una vez expuesta a grandes rasgos la normatividad de orden nacional e internacional en estos asuntos, se evidencia un conflicto de intereses entre dos órdenes, a saber: de un lado, el Código Penal es claro al afirmar que quien cultive o conserve sin permiso de autoridad competente cualquier planta de la que pueda producirse cocaína o más de un kilogramo de semillas de esta planta incurrirá en prisión de cuatro a doce años; si la cantidad de plantas excede las veinte sin sobrepasar las cien, la pena será de uno a tres años. Esta norma interna también es contraria a manifestaciones culturales como la del cultivo e ingesta de coca por parte del pueblo indígena Nasa en el departamento del Cauca.

La prohibición del cultivo y consumo, como se señaló con antelación, atiende no solo la normatividad de orden interno sino externo, como es el caso de la Junta Internacional de Fiscalización de Estupefacientes ${ }^{1}$, que recomienda eliminar el consumo tradicional de la hoja de coca en Suramérica, lo cual choca con la Constitución y la Ley colombianas que reconocen dicha práctica como una manifestación cultural de los pueblos indígenas.

\section{Formulación del problema}

Tras esta breve presentación, las preguntas problémicas sobre las que gravitará la discusión apuntarán a demostrar si el consumo y comercialización de alimentos con base en la hoja de coca puede considerarse una manifestación del patrimonio cultural

"La Junta Internacional de Fiscalización de Estupefacientes (JIFE) es un órgano de supervisión independiente y cuasi judicial para la aplicación de los tratados de fiscalización internacional de drogas. Fue establecida en 1968 de conformidad con la Convención Única sobre Estupefacientes de 1961. Sus predecesores, en virtud de los tratados de fiscalización de drogas, se remontan a la época de la Sociedad de las Naciones" (JIFE, 2012). 
inmaterial de la nación, ¿de qué manera y hasta qué punto la comunidad internacional puede prohibir y tratar de abolir el uso en el pueblo Nasa en el departamento del Cauca? Frente a los conflictos suscitados, ¿cuál es la vía más expedita que tiene el pueblo indígena Nasa para hacer valer sus pretensiones?, ¿existen límites a su autonomía en relación con el consumo de la hoja? Ahora bien, si existen normas que reconocen a la población indígena como multicultural y pluriétnica, ¿cuál debiera ser la postura del Gobierno y de la Corte Constitucional respecto a estas manifestaciones claras de rechazo y abolición de estas tradiciones por parte de la JIFE?

\section{JUSTIFICACIÓN}

Como se señaló con antelación, este trabajo de investigación centra sus reflexiones en la cultura nasa, especialmente en la ingesta de coca y sus derivados, costumbre ancestral considerada según los antropólogos, patrimonio cultural inmaterial por la mayoría de comunidades indígenas mesoamericanas. Esta práctica del pueblo Nasa del departamento del Cauca que encuentra en la hoja de coca una expresión de sus tradiciones y visiones de mundo, son incorporadas en la nueva Carta Política (artículos $1,7,8,246$, entre otros), garantizando así el derecho pleno de estas comunidades a preservar sus tradiciones, a no ser discriminada por ello, sino por el contrario, a ser tenidas en cuenta como símbolo de la multiculturalidad y orgullo de la nación por ser patrimonio cultural inmaterial. En esta medida, se espera contribuir con el análisis de los conceptos de multiculturalidad y plurietnia que se predican de los colombianos, y en especial a conceptualizar sobre el patrimonio cultural inmaterial de los pueblos indígenas.

Frente a las tendencias hegemónicas del mundo globalizado, la acción colectiva por parte de las comunidades indígenas está orientada a preservar sus tradiciones y visiones omnicomprensivas del mundo, de donde se deriva la importancia de este trabajo que se corresponde con el sentir generalizado de muchos pueblos y grupos que luchan por su reconocimiento ante el Estado. En esta medida, son beneficiarios de este proyecto académico los pueblos indígenas de Colombia que ven amenazada su tradición de consumir coca y de explotar este recurso económico con fines rituales y medicinales, que no entiende cómo la ley, la Constitución y la Jurisprudencia amparan este derecho, pero el Estado lo desconoce en los acuerdos firmados con Estados Unidos para erradicar el narcotráfico. Evidenciar este conflicto es otra de las razones que legitima la presente indagación.

\section{HIPÓTESIS}

En virtud de las discriminaciones constantes que se han hecho evidentes, frente al esfuerzo por consolidar una empresa que comercialice productos alimenticios y bebidas aromáticas basados en la hoja de coca y que generen ingresos económicos para sus integrantes, la hipótesis por demostrar se fórmula en los siguientes términos: 
es evidente la tensión entre el reconocimiento constitucional de la diversidad étnica y cultural y la protección de los derechos fundamentales, derivado de las prácticas culturales, en lo relacionado con la prohibición del uso de la hoja de coca por parte de la comunidad Nasa en el departamento del Cauca.

\section{ESTRUCTURA DE LOS ACÁPITES}

La primera parte, "Pluriversidad y reconocimiento de derechos en la Constitución Política de 1991", presenta los temas en materia de derechos, debatidos en la Asamblea Nacional Constituyente, concretamente los relacionados con:
a. diversidad étnica y cultural
b. jurisdicción indígena - autonomía
c. plurietnicidad

La segunda parte, "Mecanismos de protección nacional e internacional que prohíben el cultivo, uso y manejo de la hoja de coca en las poblaciones indígenas", enfatiza los alcances de normas en abierta contradicción con prácticas culturales ancestrales, que según antropólogos como Fernando Urbina (2011) y Serena Nanda (1987) dan sentido a la vida y constituyen un elemento cohesionador de estas comunidades. Concretamente se analizan acuerdos suscritos por Colombia, orientados a prohibir el consumo de la hoja de coca.

La tercera parte, "Prohibición del consumo de la hoja de coca a partir del Código Penal colombiano", reflexiona acerca de los alcances de la ley en estos asuntos, especialmente el Estatuto Nacional de Estupefacientes, más conocido como la Ley 30 de 1986 que tipifica el uso, manejo y consumo de la hoja de coca como un delito.

La parte final, "Los usos legales y comerciales de productos derivados de la hoja de coca en la comunidad Nasa", reconstruye la historia del proyecto comunitario Coca Nasa, desarrollado en el resguardo de Calderas, cuyos miembros no han cesado de reclamar los derechos que les asisten, y que han sido reconocidos, por demás, en la Constitución Política, la ley y la jurisprudencia.

\section{PLURIVERSIDAD Y RECONOCIMIENTO DE DERECHOS EN LA CONSTITUCIÓN POLÍTICA DE 1991}

Colombia ha tenido el mérito de ser uno de los primeros países en ratificar acuerdos internacionales sobre protección a los pueblos indígenas. Basta mencionar el Acuerdo 169 sobre Pueblos Indígenas y Tribales en Países Independientes, adoptado por la 76 reunión de la Conferencia General de la Organización Internacional del Trabajo (OIT), celebrada en Ginebra, Suiza en 1989 y aprobado mediante la Ley 21 de marzo 4 de 1991.

Este convenio promueve el derecho de dichos pueblos a asumir el control de sus instituciones, formas de vida y desarrollo económico y propugna por mantener y 
fortalecer sus identidades, lenguas y religiones en sus estilos de vida propios. El artículo $2^{\circ}$ de este acuerdo, por ejemplo, estatuye: "Los gobiernos deberán asumir la responsabilidad de desarrollar, con la participación de los pueblos interesados, una acción coordinada y sistemática con miras a proteger los derechos de esos pueblos y a garantizar el respeto de su integridad" ${ }^{2}$, mientras que el artículo $3^{\circ}$ señala que “deberán gozar plenamente de los derechos humanos y libertades fundamentales, sin obstáculos ni discriminación. Las disposiciones de este Convenio se aplicarán sin discriminación a los hombres y mujeres de esos pueblos".

En sentido histórico, la protección de los derechos y libertades fundamentales, incorporan un catálogo de principios y valores que irradian el ordenamiento jurídico ${ }^{3}$. Así, el sentido de universalidad de los derechos, conlleva abstraerse de contingencias históricas locales, políticas, raciales o de género, situación que no implica de ninguna manera el dejar de reconocer los derechos de grupos minoritarios. Ahora bien, ¿cómo conciliar los derechos fundamentales y el reconocimiento constitucional de las culturas minoritarias en Colombia? La jurisprudencia colombiana da cuenta de ello, como lo refleja el siguiente aparte de la sentencia:

Existe una tensión entre el reconocimiento constitucional de la diversidad étnica y cultural y la consagración de los derechos fundamentales. Mientras que éstos filosóficamente se fundamentan en normas transculturales, pretendidamente universales, que permitirían afianzar una base firme para la convivencia y la paz entre las naciones, el respeto de la diversidad supone la aceptación de cosmovisiones y de estándares valorativos diversos y hasta contrarios a los valores de una ética universal. Esta paradoja ha dado lugar a un candente debate filosófico sobre la vigencia de los derechos humanos consagrados en los tratados internacionales (Sentencia T-254/1994).

En esta medida, los derechos constituyen un marco universal que hace posible la convivencia pacífica de los pueblos, que acoge en buena medida los derechos fundamentales de las comunidades; sin embargo, suelen suscitarse conflictos en situaciones particulares, como la que trata la sentencia T-254/94. De otra parte, el Convenio 169 de la OIT, (1989) sobre pueblos indígenas y tribales en países independientes, establece lo siguiente:

2 Acuerdo 169 de la OIT. También el artículo 3 de este acuerdo, señala que los pueblos indígenas y tribales "deberán gozar plenamente de los derechos humanos y libertades fundamentales, sin obstáculos ni discriminaciones. Las disposiciones de este convenio se aplicarán sin discriminaciones a los hombres y mujeres de esos pueblos".

3 Además de este reconocimiento, cuentan con unos mecanismos para facilitar su defensa como son la Declaración Universal de Derechos Humanos; la Convención Internacional de Derechos Civiles y Políticos; la Convención Internacional sobre Derechos Económicos, Sociales y Culturales; la Convención para la Prevención y la Sanción del Delito de Genocidio; la Convención para la eliminación de toda forma de discriminación racial; la Convención de los Derechos del Niño; la Convención contra la Discriminación de la Educación y la Convención de la Organización Internacional del Trabajo (OIT) sobre Pueblos Indígenas y Tribales. 
Artículo $8^{\circ}$ :

1. Al aplicar la legislación nacional a los pueblos interesados deberán tomarse debidamente en consideración sus costumbres o su derecho consuetudinario.

2. Dichos pueblos deberán tener el derecho a conservar sus costumbres e instituciones propias, siempre que estas no sean incompatibles con los derechos fundamentales definidos por el sistema jurídico nacional ni con los derechos humanos internacionalmente reconocidos. Siempre que sea necesario, deberán establecerse procedimientos para solucionar los conflictos que puedan surgir en la aplicación de este principio.

3. La aplicación de los párrafos 1 y 2 de este artículo no deberá impedir a los miembros de dichos pueblos ejercer los derechos reconocidos a todos los ciudadanos del país y asumir las obligaciones correspondientes.

Artículo 9\%:

1. En la medida en que ello sea compatible con el sistema jurídico nacional y con los derechos humanos internacionalmente reconocidos, deberán respetarse los métodos a los que los pueblos interesados recurren tradicionalmente para la represión de los delitos cometidos por sus miembros.

2. Las autoridades y los tribunales llamados a pronunciarse sobre cuestiones penales deberán tener en cuenta las costumbres de dichos pueblos en la materia.

Colombia, como país que se precia de tener una de las constituciones más liberales de América, contempla en el artículo 246 referido a la jurisdicción especial indígena lo siguiente: "La ley establecerá las formas de coordinación de esta jurisdicción especial con el sistema judicial nacional". Si bien no ha habido avances en lo tocante a la armonización de estas jurisdicciones, cabe resaltar los logros que representan los artículos 7, 70 y 246 de la Constitución de 1991; la Ley 21 de 1991 por la cual se aprobó el Convenio 169 de la OIT, los principios ratificados en la Declaración de las Naciones Unidas; el artículo 11 (inciso e) de la Ley 270 de 1996 donde se reconoce la jurisdicción de las comunidades indígenas, al igual que la jurisprudencia que los incorpora como sujetos colectivos de derechos (T-380/93, C-180/05), dictamina la administración de justicia en sus propios territorios (T-266/99, T-1026/08, C-882/11) y la consulta previa como derecho fundamental (C-615/09, C-481/08, T-547/10, C-085/11), entre otros aspectos. Finalmente, cabe señalar cómo la pluriversidad y reconocimiento constitucional se plasma en los siguientes aspectos: a) Diversidad étnica y cultural; b) Jurisdicción indígena y, c) Plurietnicidad.

a) Diversidad étnica y cultural

La sentencia SU-510/1998 de la Corte Constitucional reconoce que los principios de diversidad étnica y cultural no son una mera declaración retórica de derechos, sino que obedecen "a la aceptación de la multiplicidad de formas de vida y sistemas de comprensión del mundo diferente de la cultura occidental". De otra parte, la sentencia C-370/02 considera que: 
[...] la Constitución no sólo reconoce y protege la diversidad étnica y cultural de la Nación (CP art. 7) sino que además establece que es deber del Estado proteger las riquezas culturales de la Nación (CP art. 8). Y como si fuera poco, la Carta precisa igualmente, que la "Cultura en sus diversas manifestaciones es fundamento de la nacionalidad y porque por ello el "Estado reconoce la igualdad y dignidad de todas las que conviven en el país (Constitución Política, 1991, art. 70).

El respeto a los principios y valores constitucionales ha sido incorporado en jurisprudencias distintas, entre ellas la C-370/2002, donde se hace explícito el reconocimiento a la diversidad étnica y cultural de la nación, de conformidad con el artículo 8 de la CP. Al ser la cultura el sustento de todo proyecto nacional, el "Estado reconoce la igualdad y dignidad de todas las que conviven en el país". Uno de los principios exaltados para hacer posible la defensa de la diversidad étnica y cultural de la nación, es el principio de autonomía. Así, el reconocimiento constitucional a la diversidad étnica y cultural de los pueblos indígenas es un hecho destacable en la nueva Carta Política, como una manera de preservar sus tradiciones y sistemas de mundo, gracias al desarrollo de la autonomía que ha hecho posible el desarrollo de estas iniciativas $^{4}$ (Sentencia T-380/1993).

b) Jurisdicción indígena - autonomía

El verdadero reconocimiento de la diversidad étnica y cultural de las comunidades indígenas se da a partir de dos principios constitucionales: la jurisdicción indígena y la autonomía. El primero se encuentra reconocido explícitamente en el artículo 246.

Las autoridades de los pueblos indígenas podrán ejercer funciones jurisdiccionales dentro de su ámbito territorial, de conformidad con sus propias normas y procedimientos, siempre que no sean contrarios a la Constitución y leyes de la República. La ley establecerá las formas de coordinación de esta jurisdicción especial con el sistema judicial nacional ${ }^{5}$.

En este mismo sentido se pronuncia la Sentencia T-811/2004, en la que la Corte reitera el concepto de "fuero indígena", como el derecho que tienen los miembros de estas comunidades indígenas para ser juzgados según sus autoridades, normas y procedimientos:

4 Esta sentencia considera que para hacer efectivo el reconocimiento a la diversidad étnica y cultural, debe reconocerse en el plano constitucional la autonomía, mediante personería sustantiva a las diversas comunidades indígenas, entendida esta como el mecanismo más efectivo que les confiere el goce de los derechos fundamentales y para exigir su protección cuando estos han sido violados.

5 De este artículo se derivan cuatro elementos sustanciales de la jurisdicción indígena: a) Autoridades que ejercen funciones jurisdiccionales en sus propios territorios; b) Facultad de los pueblos indígenas para crear normas según sus usos y costumbres; c) Sujeción de las jurisdicciones especiales así como los procedimientos a la Constitución y leyes de República; d) Las formas de coordinación de la jurisdicción indígena con el sistema judicial nacional, elemento que no ha tenido mayor desarrollo en Colombia, lo que ha generado situaciones encontradas entre el reconocimiento constitucional de la diversidad étnica y cultural frente a la protección de los derechos fundamentales como resultado de las prácticas culturales específicas en diversos ámbitos. 
El fuero indígena es el derecho del que gozan miembros de las comunidades indígenas, por el hecho de pertenecer a ellas, para ser juzgados por las autoridades indígenas, de acuerdo con sus normas y procedimientos, es decir por un juez diferente del que ordinariamente tiene la competencia para el efecto y cuya finalidad es el juzgamiento acorde con la organización y modo de vida de la comunidad. Este reconocimiento se impone, dada la imposibilidad de traducción fiel de las normas de los sistemas indígenas al sistema jurídico nacional y viceversa, lo cual se debe en buena medida a la gran diversidad de sistemas de resolución de conflictos por el amplio número de comunidades indígenas y a que los parámetros de convivencia en dichas comunidades se basen en concepciones distintas, que generalmente hacen referencia al "ser" más que al "deber ser", apoyados en una concepción integradora entre el hombre y la naturaleza y con un fuerte vínculo con el sistema de creencias mágico-religiosas.

También, el reconocimiento de los pueblos indígenas como sujetos autónomos de derechos lo consagra la Constitución Política en su artículo 330:

De conformidad con la Constitución y las leyes, los territorios indígenas estarán gobernados por consejos conformados y reglamentados según los usos y costumbres de sus comunidades y ejercerán las siguientes funciones:

1. Velar por la aplicación de las normas legales sobre usos del suelo y poblamiento de sus territorios.

2. Diseñar las políticas y los planes y programas de desarrollo económico y social dentro de sus territorios, en armonía con el Plan Nacional de Desarrollo.

3. Promover las inversiones públicas en sus territorios y velar por su debida ejecución.

4. Percibir y distribuir sus recursos.

5. Velar por la preservación de los recursos naturales.

6. Coordinar los programas y proyectos promovidos por las diferentes comunidades en su territorio.

7. Colaborar con el mantenimiento del orden público dentro de su territorio de acuerdo con las instrucciones y disposiciones del Gobierno Nacional.

8. Representar a los territorios ante el Gobierno Nacional y las demás entidades a las cuales se integren.

9. Las que les señalen la Constitución y la ley.

Parágrafo. La explotación de los recursos naturales en los territorios indígenas se hará sin desmedro de la integridad cultural, social y económica de las comunidades indígenas. En las decisiones que se adopten respecto de dicha explotación, el Gobierno propiciará la participación de las respectivas comunidades (Constiución Política de Colombia, 1991, Artículo 330). 
Bajo estos preceptos, la autonomía se consagra como uno de los principios que posibilitan el desarrollo de las comunidades indígenas, enfocado no solamente en el manejo de sus propios territorios, sino en la elección de sus formas particulares de autoridad, conservación de su lengua, cultura y tradiciones, prácticas médicas y educación, según sus características y visiones del mundo. Todas estas expresiones configuran el sentido de autonomía de los pueblos indígenas.

c) Plurietnicidad

El reconocimiento de la plurietnicidad constituye otro avance significativo, no solamente a los 84 pueblos raciales, sino a las comunidades room y afrodescendientes que conforman la diversidad étnica y cultural de la nación colombiana, y que según el artículo 7 de la Carta fundamental, el Estado está obligado a respetar y proteger en su existencia sino en la especificidad misma de las costumbres y prácticas culturales diversas, constitutivas de la nacionalidad colombiana, entre ellas el consumo habitual de la hoja de coca con propósitos medicinales, rituales y simbólicos. El artículo 1 constitucional describe a Colombia como Estado pluralista:

Colombia es un Estado social de derecho organizado en forma de república unitaria, descentralizado, con autonomía de sus entidades territoriales, democrática, participativa y pluralista, fundada en el respeto de la dignidad humana, en el trabajo y la solidaridad de las personas que la integran y en la prevalencia del interés general.

\section{MECANISMOS DE PROTECCIÓN NACIONAL E INTERNACIONAL QUE PROHIBEN EL CULTIVO, USO Y MANEJO DE LA HOJA DE COCA EN LAS POBLACIONES INDÍGENAS}

Algunos pueblos indígenas de Colombia consumen hoja de coca, tradición que se encuentra protegida por la Constitución Política, en especial cuando prescribe que "la cultura en sus diversas manifestaciones es fundamento de la nacionalidad"; sin embargo, siendo este consumo parte del patrimonio cultural de la nación no está incluido en la lista representativa de manifestaciones. Empero, las prohibiciones acerca del consumo y uso de la hoja de coca y sus derivados con fines rituales y simbólicos se sustentan en acuerdos que Colombia ha suscrito con Estados Unidos, en el marco de la política de erradicación de cultivos ilícitos y el tráfico de drogas, como se muestra a continuación.

\section{La Junta Internacional de Fiscalización de Estupefacientes (JIFE)}

El tema del cultivo, uso y consumo de la hoja de coca cobra importancia en instrumentos internacionales como la Convención Única sobre Estupefacientes (CUE) de las Naciones Unidas, celebrada en Nueva York el 30 de marzo de dicho año, donde las partes firmantes expresan en el preámbulo su preocupación "por la 
salud física y moral de la humanidad, y el reconocimiento de que la toxicomanía constituye un mal grave para el individuo y entraña un peligro social y económico para la Humanidad". Sobre este particular existen tres convenciones de las Naciones Unidas: la Convención Única de 1961 sobre Estupefacientes, la Convención sobre Sustancias Psicotrópicas proferida en 1971 que buscaba luchar contra el consumo de estupefacientes en los años sesenta y setenta, y la Convención de las Naciones Unidas contra el Tráfico Ilícito de Estupefacientes y Sustancias Psicotrópicas, de 1988.

Con base en estas convenciones se restringe el uso de la hoja de coca en Colombia, y en 1986 con la Ley 30 de 1986, norma que aporta las siguientes precisiones conceptuales:

ñ) Plantación: es la pluralidad de plantas, en número superior a veinte (20) de las que pueden extraerse drogas que causen dependencia.

o) Cultivo: es la actividad destinada al desarrollo de una plantación en los términos descritos en el literal anterior.

En Colombia, el Decreto 3788 de 1986 de diciembre 31 "por el cual se reglamenta la Ley 30 de 1986 o Estatuto Nacional de Estupefacientes”, estableció en su artículo 2 lo siguiente:

Para los efectos previstos en el Estatuto Nacional de Estupefacientes cuando se mencione la palabra planta se entenderá no sólo el ser orgánico que vive y crece sino también el que ha sido arrancado de la tierra o del cual se conserven sus hojas.

La anterior precisión puso en alto riesgo la libertad de los pueblos indígenas en lo que respecta al consumo inmemorial de la hoja de coca, desconociendo los tratados internacionales y las normas internas que abogan por las tradiciones que tienen un arraigo cultural ancestral. El mencionado decreto estipula lo siguiente:

Cuando únicamente se encuentren hojas de plantas de las que pueden extraerse sustancias estupefacientes, con el fin de dar aplicación al artículo 32 de la Ley 30 de 1986, se considera que cien gramos de hojas de coca en promedio corresponden a una planta. Igualmente, se considera que doscientos gramos de hojas de coca pueden producir un gramo de cocaína.

De otra parte, esta ley es clara al definir lo siguiente: "Estas plantas sólo podrán ser cultivadas previa licencia expedida por el Consejo Nacional de Estupefacientes, de acuerdo con la reglamentación que para el efecto se establezca" (art. 5). El artículo $3^{\circ}$ fija los límites de producción con fines médicos y científicos:

La producción, fabricación, exportación, importación, distribución, comercio, uso y posesión de estupefacientes, lo mismo que el cultivo de plantas de las cuales éstos se produzcan, se limitará a los fines médicos y científicos, conforme la reglamentación que para el efecto expida el Ministerio de Salud.

En el 2008 la JIFE en su informe anual afirmó que la práctica de masticar hoja de coca en Bolivia y Perú debió de haberse abolido desde 1989, en cumplimiento de los 
acuerdos suscritos, y que su uso industrial en algunos países contrariaba los tratados internacionales de lucha contra los estupefacientes, por lo que se exhortaba a los países a legislar en aras de dar cumplimiento a las normas internacionales, como lo reflejan las siguientes recomendaciones (JIFE, 2008, p. 41). Y en el informe de 2007 consignó:

216. Continúa la práctica de masticar hoja de coca en Bolivia y el Perú y, en menor medida, en otros países. La Junta señala que esa práctica debería haberse abolido, en los países en que existiera, en el curso de los 25 años siguientes a la entrada en vigor de la Convención de 1961. Como ésta entró en vigor en 1964, debería haberse puesto fin a esa práctica en 1989.

217. Además, la hoja de coca se utiliza en Bolivia y el Perú para la fabricación y distribución de mate de coca. Ese uso tampoco está en consonancia con las disposiciones de la Convención de 1961. La Junta exhorta una vez más a los Gobiernos de Bolivia y el Perú a que consideren la posibilidad de modificar la legislación nacional con objeto de abolir o prohibir las actividades que sean contrarias a la Convención de 1961, entre ellas la práctica de masticar hoja de coca y la fabricación de mate de coca y otros productos que contengan alcaloides de la coca con destino al consumo interno y a la exportación.

219. La Convención de 1988 exige que los gobiernos tipifiquen como delito en su derecho interno, cuando se cometan intencionalmente, las actividades relacionadas con la hoja de coca que sean contrarias a las disposiciones de la Convención de 1961, entre ellas, la producción, la oferta para la venta, la distribución, la venta, la entrega en cualesquiera condiciones, el corretaje, el envío, el transporte, la importación o la exportación de hoja de coca en contra de lo dispuesto en la Convención de 1961. Sin perjuicio de sus principios constitucionales y de los conceptos fundamentales de su ordenamiento jurídico, cada una de las Partes en la Convención debería tipificar como delito, cuando se cometan intencionalmente, la posesión y la adquisición de hoja de coca para el consumo personal en contra de lo dispuesto en la Convención de 1961. Los gobiernos deberían tipificar como delito en su derecho interno, cuando se cometa intencionalmente, el cultivo de arbusto de coca.

431. En diciembre de 2006, en consonancia con su estrategia de fiscalización de drogas, el Gobierno de Bolivia inauguró una de las tres plantas previstas para la producción de hoja de coca con fines industriales. La Junta observa con preocupación que el uso de la hoja de coca con fines industriales, por ejemplo, la producción de té o harina de coca, contraviene los tratados de fiscalización internacional de drogas. La Junta recuerda al Gobierno de Bolivia y a los gobiernos de los demás países interesados que el uso y la importación de hoja de coca de la que no se haya extraído la cocaína con fines que no sean los permitidos con arreglo a la Convención de 1961 infringen las disposiciones de esos tratados. 
Recomendación 7: Continúa la práctica de masticar hoja de coca en Bolivia y el Perú. Los países de la región sufren las consecuencias de la fabricación ilícita y el tráfico de cocaína. La Junta exhorta a los Gobiernos de Bolivia y el Perú a que adopten medidas sin demora con miras a abolir los usos de la hoja de coca que sean contrarios a la Convención de 1961, incluida la práctica de masticarla. Los Gobiernos de esos países y de Colombia deben redoblar sus esfuerzos contra la fabricación ilícita y el tráfico de cocaína. La Junta hace un llamamiento a la comunidad internacional para que preste asistencia a esos países a fin de alcanzar esos objetivos.

El cultivo de la hoja de coca para usos tradicionales es considerado en algunos países semilegal, pero en Colombia se ha tipificado como delito. Al respecto, en el estudio titulado El negocio transatlántico de la cocaína: opciones europeas ante las nuevas rutas del narcotráfico (Brombacher y Maihold, 2012) afirman:

Dado el carácter semilegal del cultivo y la ausencia de campañas masivas de erradicación, en Bolivia y Perú la siembra de coca no ha proliferado tanto como en Colombia, concentrándose más en determinadas regiones. El cultivo legal abastece la demanda de coca para usos tradicionales - mascar coca, infusiones, fines medicinales y rituales- tienen, a diferencia de Colombia, amplia difusión en Bolivia y Perú.

Estos autores se han ocupado de analizar el mercado de drogas ilícitas frente al papel que cumplen los organismos internacionales encargados de erradicar su uso y comercio en Europa, así como las rutas de destino.

\section{Prohibición del consumo de la hoja de coca a partir del Código Penal colombiano}

No son pocas las comunidades indígenas suramericanas que han cultivado desde épocas remotas la planta de coca, considerada sagrada, y aprovechado sus hojas en una diversidad de usos: alimento, medicina, medio de pago y elemento ritual y simbólico, entre otros (Wollrad, Maihold y Mols, 2011). En Colombia son muchas las comunidades indígenas que tradicionalmente la consumen, sin embargo, cultivar la planta es considerado un delito según el artículo 375 del Código Penal.

A la luz del Código Penal, quien cultive o conserve sin permiso de autoridad competente cualquier planta de la que pueda producirse cocaína o más de un kilogramo de semillas de dicha planta, incurrirá en prisión de cuatro (4) a doce (12) años; además de lo anterior, si la cantidad de plantas excede de veinte (20) sin sobrepasar las cien (100) la pena será de uno (1) a tres (3) años. Esta norma está en abierta contradicción con una manifestación cultural como la del cultivo e ingesta de 
coca por parte del pueblo indígena Nasa del departamento del Cauca. El artículo 7 del Consejo Nacional de Estupefacientes (CNE) es más benévolo con las comunidades:

Artículo 7o. El Consejo Nacional de Estupefacientes reglamentará los cultivos de plantas de las cuales se produzcan sustancias estupefacientes y el consumo de éstas por parte de las poblaciones indígenas, de acuerdo con los usos y prácticas derivadas de su tradición y cultura.

Las tensiones entre estas prácticas ancestrales y las exigencias de la JIFE cada vez más se agudizan, en la medida que recomiendan acabar con el consumo tradicional de la hoja de coca en Suramérica, entrando en abierta contradicción con la Constitución y la Ley que lo reconocen como una manifestación cultural de los pueblos indígenas.

Las experiencias exitosas que se han dado principalmente en Bolivia y Perú, han sido retomadas en países como Colombia, por parte del pueblo Nasa. Un ejemplo es la batalla legal que Bolivia ha entablado con la multinacional CocaCola a partir de una audiencia pública que convocó a más de 400 dirigentes de los productores, comercializadores y consumidores de la hoja de coca, en que se aprobó de manera conjunta una resolución en la que se solicitó a la multinacional CocaCola Company prescindir del nombre de la planta sagrada en sus productos. Otro de estos pronunciamientos consistió en declarar patrimonio cultural boliviano la hoja de coca, cuestionada seriamente por los conservadores de dicho país. Este viejo debate se revivió después de que la presidenta de la Comisión de la Coca en la Asamblea Constituyente de Bolivia y exdirigente cocalera, Margarita Terán, pidió que se emprendieran acciones orientadas a revalorizar la hoja de coca, máxime cuando la multinacional Coca-Cola se servía de este producto para la producción de la bebida, planta que compró durante años en Bolivia. Esta información fue desmentida de inmediato por la firma, que aseveró su retiro en el año 1929 y sustituida por otros productos.

A pesar de estas declaraciones, el viceministro de Defensa Social, Ernesto Justiniano, cuando en el 2002 era funcionario encargado de la lucha contra el narcotráfico, aseveró que esta dependencia bajo su cargo había autorizado la exportación de aproximadamente 159 toneladas de hoja de coca a Estados Unidos, destinadas a la fabricación de la Coca-Cola, una de las bebidas más tradicionales del mundo. La compra de hoja de coca con destino a la producción de esta bebida gaseosa fue corroborada en un informe de la Comisión Nacional para el Desarrollo y Vida sin Drogas de Perú, donde se señala que la multinacional Coca-Cola adquirió en el Perú 115 toneladas de hoja de coca al año y a Bolivia 105 toneladas (Stefanoni, 2014). 


\section{Los usos legales y comerciales de productos derivados de la hoja de coca en la comunidad $\mathrm{Nasa}^{6}$}

A finales de los años noventa, surgió en el resguardo indígena de Calderas la propuesta de crear una empresa comercializadora de productos derivados de la hoja de coca, denominada Coca Nasa, como una manera de superar la marginalidad social de esta comunidad y derivar ingresos económicos que le permitiera elevar el nivel de vida; además de generar cierta rentabilidad, esta iniciativa tuvo como propósito reivindicar el uso tradicional de esta planta en todas las culturas mesoamericanas (Pachón, 2000). Esta propuesta de diversificar los productos, además de generar ingresos económicos entre los miembros de la comunidad indígena, pretendía ser una alternativa para salirle al paso a los grupos ilegales y narcotraficantes que han utilizado a estas comunidades con fines meramente comerciales.

La solicitud del presidente de la Organización Nacional Indígena de Colombia (ONIC), Armando Valbuena, de emitir un concepto acerca de los usos tradicionales y milenarios de la planta de coca en los pueblos indígenas, la directora del Instituto Colombiano de Antropología e Historia (ICANH), María Victoria Uribe, respondió:

El uso de la planta de coca como elemento alimenticio, medicinal y religioso entre las comunidades indígenas suramericanas de los Andes y del noroccidente amazónico está ampliamente documentado en los textos sagrados y narraciones indígenas, en las primeras crónicas españolas y de diversos viajeros, en estudios antropológicos contemporáneos y en las declaraciones de las organizaciones y autoridades indígenas.

La planta de coca y sus hojas son de gran importancia para la cosmología y la religión de las comunidades indígenas. La masticación de hojas de coca es una práctica importante dentro de los rituales y dentro de las ceremonias de los chamanes o especialistas religiosos y médicos (ICANH, 2000).

La Asociación de Cabildos Juan Tama en Resolución N. 001 de 2002 otorgó permiso al resguardo de Calderas para utilizar la hoja de coca en la producción de aromáticas y, además, elevó una solicitud ante el Instituto Nacional de Vigilancia de Medicamentos y Alimentos (INVIMA) con el propósito de legalizar los requerimientos fitosanitarios para la comercialización de productos derivados de la hoja de coca como galletas, vino, té, infusiones y una bebida gaseosa que en el mercado se conoce con el nombre de Coca Sek. La Resolución N. 001 de 2002 fue publicada en el Diario Oficial 45.029, cumpliendo así con los trámites de rigor

6 El pueblo Nasa, también denominado Páez, tiene su principal asentamiento en el resguardo de Tierradentro, terrenos que comprenden los actuales departamentos de Cauca y Tolima. "Los municipios del departamento del Cauca donde se encuentra ubicada la población Nasa o Páez son 16: Buenos Aires, Caldono, Caloto, Corinto, El Tambo, Inzá, Jambaló, Miranda, Morales, Páez, Popayán, Puracé, Santander de Quilichao, Silvia, Toribío y Totoro". Diagnóstico de la situación del pueblo indígena Nasa o Páez. Observatorio del Programa Presidencial de Derechos Humanos y DIH, 2010. Consultado el 20 de junio de 2014. 
exigidos por el Código Contencioso Administrativo para dar cumplimiento a los actos oficiales. El INVIMA en principio no presentó objeción alguna sobre el hecho de poner en supermercados y tiendas naturistas estos productos.

Posteriormente, en un informe del 8 de junio de 2004, el INVIMA, en cabeza del su director, el doctor Miguel Rueda, reconoció la Resolución emanada por la Asociación de Cabildos y en uno de sus apartes afirmó lo siguiente:

Las características de este tipo de comunidades implican un acatamiento a las normas por cada uno de los miembros de la comunidad lo cual garantiza en forma importante que ante un eventual acuerdo para la comercialización de la coca en forma lícita el Gobierno del Cabildo asume el control para evitar que se desvíe su producción al campo de lo ilícito.

Este documento otorgó viabilidad y alcance al proyecto comunitario, hecho que brindó a la comunidad cierto nivel de seguridad jurídica. La producción de la gaseosa mereció un editorial del diario de mayor circulación nacional, bajo el título La CocaCola de los indígenas (El Tiempo, 2005) ${ }^{7}$.

Un año después, en el 2006, la multinacional Coca-Cola Company demandó a los indígenas por el uso de la palabra "coca" en sus productos, asunto jurídico que se decidió finalmente a favor de los demandados. A comienzos de 2007, la asesora jurídica del INVIMA, Carolina Contreras, emprendió una serie de acciones orientadas a restringir a los territorios indígenas el consumo de los productos fabricados por la firma Coca Nasa en el resguardo de Calderas, la bebida gaseosa Coca Sek, galletas, infusiones y bebidas aromáticas, entre otros. Los operativos con el propósito de decomisar estos productos del mercado se llevaron a cabo inicialmente en el Centro Comercial Chipi Chape de la ciudad de Cali.

A raíz de estos incidentes la firma Coca Nasa inició una batalla jurídica por la restricción anotada y por haber sido puesta en la picota pública, no solo ante organismos internacionales como la JIFE, sino frente al ordenamiento jurídico colombiano que tipifica la plantación y uso de la hoja de coca como un delito, lo que implica que se equipare esta comunidad con grupos de narcotraficantes. De otra parte, tal pronunciamiento sugiere que el comercio de productos por parte de la comunidad indígena Nasa, es contrario a la Convención de 1961, hecho que puso en aprietos a la Asociación de Cabildos y la comunidad en general.

Para la comunidad indígena páez es inadmisible que después del reconocimiento público recibido en el 2004, la interpretación del acto administrativo se asumió de manera distinta tres años después, violando todos los marcos constitucionales y

$7 \quad$ En relación con la iniciativa de producir bebidas refrescantes como la gaseosa Coca Sek, el día 16 de diciembre de 2005, el diario El Tiempo registró este informe noticioso, acerca de esta bebida con base en la hoja de coca entre los paeces. "La comunidad indígena de los paeces está produciendo en Tierradentro (Cauca) una gaseosa que sus fabricantes aconsejan como refrescante y surtidora de energía. Se llama Coca Sek y tanto su receta como su proceso de elaboración pertenecen a la reserva industrial de los resguardos de Calderas de Inzá, que es donde empieza a elaborarse la nueva bebida, por ahora en número de tres mil unidades. Se trata, como lo proclama el lema comercial, de un "refresco de hoja de coca". La base de la receta es el tradicional arbusto andino, y ya está calculado que tres mil botellas consumen doce arrobas de hoja de coca". 
legales. En respuesta al pronunciamiento del INVIMA los responsables del proyecto Coca Nasa, Fabiola Piñacué Achicué y David Curtidor Argüello, enviaron una comunicación el 25 de mayo de 2006 a la doctora Josefina Araújo Baute, directora de Asuntos Étnicos del Ministerio del Interior, en donde expusieron lo siguiente:

Pretenden estos funcionarios desconocer los acuerdos con anteriores administraciones e interpretan las normas de una manera que resulta desafortunada, planteando que la norma de las autoridades indígenas sólo tendrá validez en territorios indígenas.

Ante este cambio de actitud hemos acordado con estos funcionarios del INVIMA, hacer consultas a diferentes autoridades que permitan aclararles la posibilidad de que normas expedidas por autoridades indígenas pueden tener alcance nacional e impedir que con el retiro de los productos del comercio formal se causen irreparables daños y se comprometan derechos fundamentales de varias comunidades indígenas de la zona de Tierradentro en el Cauca, como pueden ser el de la subsistencia y el de la propia identidad cultural, entre otros.

La comunidad indígena del resguardo de Calderas instauró en el año 2007 una acción de tutela, en la que solicitaba revocar la restricción del uso y la comercialización de los productos alimenticios derivados de la hoja de coca, producidos por ella en estos territorios. Los argumentos de esta decisión se vieron influenciados, posiblemente por las recomendaciones de la Dirección Nacional de Estupefacientes al director general del INVIMA un año después, donde se recomendaba tomar "medidas pertinentes ante los productos que a base de hoja de coca (sic) se producen y comercializan actualmente sobre el territorio nacional" (Dirección Nacional de Estupefacientes, 2006) ${ }^{8}$.

En la información cruzada entre las instituciones y los responsables del proyecto con las diversas instancias como la Dirección de Asuntos Étnicos del Ministerio del Interior, es evidente el desconocimiento y el temor de ciertos organismos a proceder con el reconocimiento legal de una iniciativa legítima, que como se ha dicho con antelación, buscaba el comercio de productos derivados de la hoja de coca. El presidente de la República, Andrés Pastrana Arango (1998-2002) dio instrucciones al INVIMA para que expidiera el registro sanitario, cuando su director, Miguel Rueda, había adelantado los procedimientos de rigor como la elaboración de informes y material audiovisual, en los que daba cuenta de la inocuidad de la hoja de coca y la viabilidad del proyecto comunitario para hacerlo extensivo a los territorios no indígenas. No obstante la orden presidencial, algunos funcionarios asumieron una postura, más que tímida poco comprometedora, arguyendo que "esto podría entenderse como la legalización de las drogas y que en consecuencia no era políticamente presentable"

8 Oficio SEI/343/06 de diciembre 4 de 2006, emanado de la Dirección Nacional de Estupefacientes. De este oficio no tuvo conocimiento la comunidad Páez sobre quien recayó la decisión de retirar los productos comercializados fuera de los resguardos. 
(Resguardo de Calderas, 2006) ${ }^{9}$. Ahora bien, si el presidente de la república en aquel entonces tenía conocimiento de esta supuesta resolución, ¿por qué algunos funcionarios de la Dirección Nacional de Estupefacientes y el Consejero de Seguridad Nacional recomendaron a las autoridades indígenas la expedición del acto administrativo que convalidaban esos registros? La respuesta parece ser que el presidente fue víctima de un engaño por parte de quienes le informaron que el INVIMA había otorgado el registro sanitario, cuando en realidad lo que esta entidad hizo fue reconocer un acto administrativo emanado de las autoridades indígenas.

La interpretación que se deriva de lo anterior, consiste en que al parecer, las recomendaciones hechas por la Dirección Nacional de Estupefacientes al INVIMA, estaban orientadas a legalizar tímidamente el consumo de plantas ilícitas, por lo que en un futuro tendría que hacerla extensiva a las poblaciones no indígenas.

La asesora jurídica del INVIMA, Carolina Contreras, en entrevista radial concedida a la FM el día 12 de marzo de 2003, expresó que estas medidas no afectaban las prácticas ancestrales de la comunidad indígena ${ }^{10}$, pero fijarle límites a la producción y comercialización, es una manera de restringir el derecho a la autonomía a partir de la generación de ingresos derivados de una actividad económica alternativa. En otro de los apartes, el INVIMA enfatiza que "los actos emanados por las autoridades indígenas carecen de efectos en el resto del territorio nacional", asumiendo competencias ajenas a su jurisdicción contenciosa administrativa al decidir sobre el alcance y vigencia de un acto administrativo de otra entidad pública.

En síntesis, el INVIMA asumió funciones que no eran de su jurisdicción contenciosa administrativa y controvierte por demás una recomendación que le fue hecha por el Ministerio del Interior y Justicia, por solicitud de los responsables del proyecto Coca-Nasa.

Posteriormente, en un comunicado firmado por la subdirectora de Medicamentos y Productos Biológicos y el subdirector de Alimentos y Bebidas Alcohólicas, el INVIMA comunica a todas las secretarías departamentales y municipales de salud que:

[...] los productos derivados de la coca (té, aromáticas, galletas, gaseosa, dulces, etc.) elaborados y comercializados en los resguardos indígenas, NO pueden ser comercializados ni publicitados en el resto del territorio nacional..." y ordena que "....en caso de encontrar productos de este tipo fuera de los territorios autorizados, es necesario aplicar las medidas sanitarias del caso e iniciar los procesos sancionatorios correspondientes, de acuerdo a la normatividad vigente (INVIMA, 2007).

9 Oficio despachado desde el resguardo de Calderas, Tierradentro, el 25 de mayo de 2006 a la doctora Josefina Araujo Baute, directora Asuntos Étnicos del Ministerio del Interior, firmada por los responsables del proyecto Coca Nasa, Fabiola Piñacué Achicué y David Curtidor Argüello.

10 Entrevista concedida a la FM, el 12 de marzo de 2003 a las 9:00 a.m. 
Frente a esta decisión, el 20 de junio de 2007, la directora del Instituto Colombiano de Antropología e Historia (ICANH) María Clemencia Ramírez, solicitó a la Corte Constitucional revisar el fallo de la tutela interpuesta por las comunidades indígenas del Cauca el 6 de junio del mismo año por cuanto:

En consecuencia, la medida del INVIMA vulnera los derechos de los indígenas al trabajo, al desarrollo económico y a la participación en la economía de mercado, y se convierte en un acto de discriminación abierta y desde el Estado, a su participación en esferas de la vida moderna de la nación. De manera paradójica, esta discriminación se presenta amparada en el supuesto reconocimiento de su diferencia cultural y de la multiculturalidad (ICANH, 2007).

De conformidad con lo anterior, es claro que el reconocimiento de la multiculturalidad se ha dado a partir no solo de los pronunciamientos de la Corte Constitucional sino de la Constitución Política, situación que ha propiciado encuentros entre las comunidades minoritarias motivadas por intereses económicos particulares. La dinámica capitalista no está dispuesta a reconocer el uso de esta planta como una alternativa económica indigenista, como lo contempla la JIFE, amparo legal incorporado en el Estatuto Nacional de Estupefacientes (Ley 30 de 1986) y la Corte Constitucional en varios de sus pronunciamientos, en especial la sentencia C-176/1994'11.

En lo relacionado con el pronunciamiento del INVIMA, también manifestó su inconformidad el director de la Oficina de Asesoría Jurídica del Ministerio de Cultura, doctor Juan Manuel Vargas Ayala, en comunicado el 25 de agosto de 2008, en que responde a la solicitud de la doctora Gloria Patricia Puerta Jiménez, adscrita a la Procuraduría Segunda para la Vigilancia Administrativa, en el sentido de valorar lo tocante al reconocimiento cultural del consumo de bebidas y productos derivados de la hoja de coca, no alucinógenos, para las comunidades indígenas y su posible expansión cultural en territorios no indígenas. Su respuesta concluye en los siguientes términos:

Visto lo anterior, este Ministerio considera que el reconocimiento cultural del consumo de bebidas y productos derivados de la hoja de coca, no alucinógenos, para las comunidades indígenas y su posible expansión cultural en territorios no indígenas, es un hecho a no dudar, afirmación que se desprende del análisis constitucional y legal hecho por la Corte, y del uso de la hoja de coca en notoria ejecución permanente (Ministerio de Cultura, 2008).

La Procuraduría Delegada en materia de Derechos Humanos y Asuntos Étnicos, en igual sentido, solicitó concepto a Sorely Paredes Vargas, subdirectora de Asuntos Indígenas del Ministerio de Cultura. La funcionaria, tras hacer un análisis

11 Magistrado Sustanciador: Alejandro Martínez Caballero. Revisión constitucional de la Ley 67 de 23 de agosto de 1993 "por medio de la cual se aprueba la 'Convención de las Naciones Unidas contra el tráfico ilícito de estupefacientes y sustancias sicotrópicas', suscrito en Viena el 20 de diciembre de 1988". REF: Expediente No. L.A.T.-021. 
antropológico, sociológico y jurídico, consideró plausible dar cumplimiento a la solicitud de los indígenas, en virtud de la resolución emanada de la Asociación de Cabildos y expresó:

Igualmente y teniendo en cuenta lo expuesto en el Oficio del 8 de junio de 2004 del INVIMA, con el cual se reconoce la existencia de la Resolución N. ${ }^{\circ}$ 001 de 2002, expedida por la Asociación de Cabildos Juan Tama, se considera necesario dar trámite por parte de esa entidad, para el cumplimiento de las normas fitosanitarias (Ministerio de Cultura, 2008).

El anterior es otro de los documentos donde se exponen las motivaciones que respaldan las iniciativas de la comunidad Nasa o Páez, ante las presiones constantes ejercidas por organismos nacionales como el INVIMA y la legislación colombiana que contempla como un hecho punible el uso, manejo y consumo de sustancias psicotrópicas. En este punto es preciso hacer claridad entre el uso tradicional de la hoja de coca con fines medicinales, terapéuticos y nutricionales, y los usos ilícitos con fines económicos, actividad que ha estado asociada a grupos de narcotraficantes. Cabe también hacer la distinción entre la hoja de coca y la cocaína: la primera forma parte de las tradiciones ancestrales de las culturas mesoamericanas inclusive desde mucho antes de la llegada de los españoles; a diferencia de la segunda es sustancia alcaloide extraída de la planta para el consumo ilícito, como lo manifiesta la sentencia C-176/1994.

\section{CONCLUSIONES}

Las democracias modernas han avanzado en materia de derechos, tanto que se establecen límites a las culturas minoritarias cuando colisionan con ordenamientos constitucionales, pero puedeocurrirtambiénque seadopten medidas inconstitucionales en detrimento de estas como el caso en el que se centra esta investigación a saber: la prohibición del cultivo, masticación y producción de derivados de la hoja de coca, como es habitual en la comunidad Nasa del Cauca. En esta situación particular, uno de los recursos para hacer la defensa de estos derechos son los tribunales internacionales que bien pueden ratificar la decisión asumida por los jueces, o por el contrario, avalar el concepto de que la decisión judicial es contraria al derecho consuetudinario, lo que obligaría al Estado a revisar esta decisión y modificar la normatividad existente, con el fin de armonizar estas prácticas con el derecho ordinario.

La prohibición de poner a la venta productos derivados de la "planta sagrada" lesiona gravemente los intereses económicos y culturales del pueblo Nasa o Páez, además de poner en alto riesgo la integridad étnica y cultural de la comunidad al asociar los productos derivados de la hoja de coca con el mercado ilícito que ejercen los narcotraficantes; del mismo modo se ve cuestionado el sentido de autonomía de las comunidades indígenas, como en reiteradas veces lo cita la jurisprudencia colombiana. 
La decisión del INVIMA de restringir la venta de tales productos al espacio que habita la comunidad nasa no solo lesiona gravemente sus intereses, sino que ignora otras formas simbólicas de apropiación de lugares sagrados que no siempre se encuentran circunscritos a un determinado espacio geográfico, como lo reitera la sentencia T-778/2005, en lo tocante al ámbito de aplicación del derecho a la identidad cultural.

La negativa del INVIMA, contempla no solamente la restricción de los productos en territorios no indígenas, sino la exclusión de campañas publicitarias orientadas a promover su consumo, decisión que va en contravía no solo de acuerdos nacionales e internacionales, sino que resulta violatoria de los principios 7, 8, 9, 70, 286 y 330 de la Constitución Política y va en contravía de los avances logrados en la sentencia C-176/1994.

\section{REFERENCIAS}

Acuerdo 169 de la Organización Internacional del Trabajo (OIT).

Asociación de Cabildos Juan Tama. Resolución N. 001 de 2002.

Brombacher, D. (2013). Cultivo ilegal de drogas y opciones legales de regulación: comparación entre coca y adormidera. En Mathieu, H. y Niño, C. (eds.). De la represión a la regulación: propuestas para reformar las políticas contra las drogas. Programa de Cooperación en Seguridad Regional. Bogotá.

Brombacher y Maihold (2012). El negocio transatlántico de la cocaína: opciones europeas ante las nuevas rutas del narcotráfico. Madrid: Real Instituto Elcano de Estudios Internacionales y Estratégicos.

Convención de las Naciones Unidas contra el Tráfico Ilícito de Estupefacientes y Sustancias Psicotrópicas de 1988.

Convención sobre Sustancias Psicotrópicas de 1971.

Convención Única de 1961.

Dirección Nacional de Estupefacientes. Oficio SEI/343/06 de diciembre 4 de 2006.

Informe de la Junta Internacional de Fiscalización de Estupefacientes. Publicación de las Naciones Unidas. http://www.incb.org/documents/Publications/ AnnualReports/AR2013/Spanish/AR_2013_S.pdf (Consultado en julio 21 de 2014)

Instituto Colombiano de Antropología e Historia (ICANH). Oficio de junio 20 de 2007 de la directora general, María Clemencia Ramírez. Referencia: Solicitud de revisión del fallo de la tutela interpuesta por las comunidades indígenas del Cauca el 6 de junio de 2007. Oficio N. 1644169 de junio 20 de 2007.

Instituto Colombiano de Antropología e Historia (ICANH). Oficio ICANH-120-2000 de octubre 30 de 2000.

Instituto Nacional de Vigilancia de Medicamentos y Alimentos (INVIMA). Dirección General. Oficio DG 100-00131-04 el día 8 de junio de 2004. 
Instituto Nacional de Vigilancia de Medicamentos y Alimentos (INVIMA). Subdirección de Medicamentos y Productos Biológicos y Subdirector de Alimentos y Bebidas Alcohólicas. Oficio V.C.M-601-0294-07 de enero 31 de 2007.

Ley 30 de 1986 o Estatuto Nacional de Estupefacientes.

Ministerio de Cultura. Oficina de Asesoría Jurídica, doctor Juan Manuel Vargas Ayala. Oficio de agosto 25 de 2008. Respuesta a la solicitud que hiciera la doctora Gloria Patricia Puerta Jiménez, adscrita a la Procuraduría Segunda para la Vigilancia Administrativa, organismo que solicitó su valoración al Ministerio de Cultura en lo tocante al reconocimiento cultural del consumo de bebidas y productos derivados de la hoja de coca, no alucinógenos, para las comunidades indígenas y su posible expansión cultural en territorios no indígenas. Expediente N. $172003-2008$.

Ministerio de Cultura. Subdirección de Asuntos Indígenas, doctora Sorely Paredes Vargas. Respuesta en atención a un comunicado donde se le solicitó emitir concepto a la Procuraduría Delegada en materia de Derechos Humanos y Asuntos Étnicos, doctora Clara Patricia Linares Prieto, sobre el reconocimiento cultural del consumo de bebidas y productos derivados de la hoja de coca, no alucinógenos, para las comunidades indígenas y su posible expansión cultural en territorios no indígenas. Oficio signado el día viernes 12 de agosto de 2008 . Of 106-16565-DET-1.

Nanda, S. (1987). Antropología cultural: Adaptaciones socioculturales. México: Grupo Editorial Iberoamérica.

Pachón, X. (2000). Los Nasa o la gente Páez. Geografía Humana de Colombia. T. IV. Vol. II. Bogotá. Instituto Colombiano de Cultura Hispánica.

Presidencia de la República (2010). Observatorio del programa presidencial de derechos humanos y DIH. Diagnóstico de la situación del pueblo indígena Nasa o Páez. http://historico.derechoshumanos.gov.co/Observatorio/Documents/2010/ DiagnosticoIndigenas/Diagnostico_NASA-P\%C3\%81EZ.pdf. (Consultado el 20 de agosto de 2014).

Sentencia T-380/1993 Corte Constitucional. M. P. Eduardo Cifuentes Muñoz. Expediente T-13636.

Sentencia C-176/1994. Corte Constitucional. M. S. Alejandro Martínez Caballero. Expediente N. ${ }^{\circ}$ L.A.T.-021.

Sentencia T-254/1994. Corte Constitucional. M. P. Eduardo Cifuentes Muñoz. Expediente T-30116.

Sentencia SU-510/1998. Corte Constitucional. M. P. Eduardo Cifuentes Muñoz. Expediente T-141047.

Sentencia C-370/2002, Corte Constitucional. M. P. Eduardo Montealegre Lynett. Expediente D-3751. 
Sentencia T-811/2004. Corte Constitucional. M. P. Jaime Córdoba Triviño. Expediente T-891563.

Stefanoni, P. Bolivia ahora quiere registrar la palabra "coca" como marca. El Clarín. La Paz, Bolivia. elmundo@clarin.com. http://edant.clarin.com/diario/2007/03/16/ elmundo/i-02603.htm Recuperado el 7 de octubre de 2014.

Urbina Rangel, F. La coca, palabras hojas para cuidar el mundo. Open Journal Systems. http://revistas.unal.edu.co/index.php/maguare. Universidad Nacional de Colombia, 2011.

Wollrad, D., Günther, M., y Manfred, M. (Eds.). (2011). La agenda internacional de América Latina: entre nuevas y viejas alianzas. Argentina: Fundación Foro Nueva Sociedad. 